\title{
Article \\ Effects of Vehicle Load on Emissions of Heavy-Duty Diesel Trucks: A Study Based on Real-World Data
}

\author{
Xin Wang ${ }^{1}$, Guohua Song ${ }^{1, *}$, Zhiqiang Zhai ${ }^{1,2}$, Yizheng $W^{1}{ }^{1}$, Hang Yin ${ }^{3}$ and Lei $Y_{u}{ }^{1,4,5} \mathbb{D}$ \\ 1 Key Laboratory of Transport Industry of Big Data Application Technologies for Comprehensive Transport, \\ Beijing Jiaotong University, 3 Shangyuancun, Haidian District, Beijing 100044, China; \\ 18114044@bjtu.edu.cn (X.W.); zhaizq@bjtu.edu.cn (Z.Z.); wuyizheng@bjtu.edu.cn (Y.W.); Lei.Yu@tsu.edu (L.Y.) \\ 2 Department of Civil \& Mineral Engineering, University of Toronto, 35 St. George Street, \\ Toronto, ON M5S 1A4, Canada \\ 3 State Environmental Protection Key Laboratory of Vehicle Emission Control and Simulation (VECS), \\ Chinese Research Academy of Environmental Sciences, 8 Dayang Fang, Chaoyang District, \\ Beijing 100012, China; yinhang@vecc-mep.org.cn \\ 4 Department of Transportation Studies, Texas Southern University, 3100 Cleburne Avenue, \\ Houston, TX 77004, USA \\ 5 School of Traffic and Transportation, Xuchang University, Xuchang 461000, China \\ * Correspondence: GhSong@bjtu.edu.cn
}

\section{check for}

updates

Citation: Wang, X.; Song, G.; Zhai, Z.; Wu, Y.; Yin, H.; Yu, L. Effects of Vehicle Load on Emissions of Heavy-Duty Diesel Trucks: A Study Based on Real-World Data. Int. J. Environ. Res. Public Health 2021, 18, 3877. https://doi.org/10.3390/ ijerph18083877

Academic Editors: Gianluigi de Gennaro, Jolanda Palmisani and Alessia Di Gilio

Received: 26 February 2021

Accepted: 1 April 2021

Published: 7 April 2021

Publisher's Note: MDPI stays neutral with regard to jurisdictional claims in published maps and institutional affiliations.

Copyright: (c) 2021 by the authors. Licensee MDPI, Basel, Switzerland. This article is an open access article distributed under the terms and conditions of the Creative Commons Attribution (CC BY) license (https:// creativecommons.org/licenses/by/ $4.0 /)$.
Abstract: Vehicle loads have significant impacts on the emissions of heavy-duty trucks, even in the same traffic conditions. Few studies exist covering the differences in emissions of diesel semi-trailer towing trucks (DSTTTs) with different loads, although these vehicles have a wide load range. In this context, the operating modes and emission rates of DSTTTs were analyzed under varying loads scenarios to understand the effect of vehicle loads on emission factors. First, second-by-second field speed data and emission data of DSTTTs with different loads were collected. Then, the methods for calculating the scaled tractive power (STP) and the emissions model for DSTTTs were proposed to evaluate the effect of different loading scenarios. The STP distributions, emission rate distributions, and emission factor characteristics of different loaded trucks were analyzed and compared. The results indicated that the STP distributions of DSTTTs that under the unloaded state were more narrow than those under fully loaded or overloaded conditions. The emission rates of carbon dioxide $\left(\mathrm{CO}_{2}\right)$, carbon monoxide (CO) and total hydrocarbon (THC) for DSTTTs under a fully loaded state were significantly higher than those under an unloaded state. However, due to the influence of exhaust temperature, the emission rates of nitrogen oxides $\left(\mathrm{NO}_{\mathrm{x}}\right)$ among fully loaded trucks were lower than those under the unloaded state when STP bin was above $4 \mathrm{~kW} /$ ton. The emission factors of $\mathrm{CO}_{2}, \mathrm{CO}, \mathrm{THC}$, and $\mathrm{NO}_{\mathrm{x}}$ for fully loaded trucks demonstrated the largest increases at low-speed intervals $(0-30 \mathrm{~km} / \mathrm{h})$, which rose by $96.2 \%, 47.9 \%, 27.8 \%$, and $65.2 \%$, respectively.

Keywords: diesel semi-trailer towing trucks; vehicle load; STP distribution; emission rates; emission characteristics

\section{Introduction}

Heavy-duty trucks (HDTs) are major contributors to urban traffic pollution. In China, HDTs emit $16.8 \%$ of carbon monoxide (CO), $6.9 \%$ of total hydrocarbon (THC), $57.8 \%$ of nitrogen oxides $\left(\mathrm{NO}_{\mathrm{x}}\right)$, and $66.3 \%$ of particulate matter $(\mathrm{PM})$ of the total motor vehicle emissions, despite only constituting $3.1 \%$ of the vehicle population [1]. Hence, to control urban traffic emissions, it is crucial to accurately assess and strictly monitor the emissions of heavy-duty diesel trucks (HDDTs). However, HDDTs have a wide load range-for example, diesel semi-trailer towing trucks (DSTTTs) have a load difference of 34 tons between unloaded and fully loaded conditions-and the variety in load states can significantly impact the accuracy of emissions estimates [2-4]. Few existing emission models are available to calculate the emissions of DSTTTs while considering different load states and, 
as a result, emissions are often misestimated, which may mislead or complicate emission control policies. HDDTs contribute the most $\mathrm{NO}_{\mathrm{x}}$ in urban environments and it is predicted that their population and vehicle kilometers traveled will continue to rise, leading to everincreasing emissions [5,6]. Thus, the accurate estimation of HDDTs emissions is crucial for the proper design of management and control schemes for HDDTs. This study sought to analyze the effect of load on emission assessments and attempted to widen the applicability of the HDDTs emission model.

HDDTs emissions measurements are typically performed using engine dynamometers, tunnel studies, remote sensing, and portable emissions monitoring systems (PEMS) [7-9]. The engine dynamometer test cycle is based on a specific driving cycle in the laboratory, and it is typically considered that such cycles do not represent the full range of realworld vehicle operating modes [10]. Meanwhile, tunnel testing is performed by installing devices within the tunnel to test the average emissions of all passing vehicles. In this regard, they may not be representative of emissions under all field operating conditions, and make it difficult to distinguish vehicle types [11]. Remote sensing measurements can offer a snapshot of active vehicle emission concentrations at a specific location and, therefore, might not represent an entire operating cycle [12]. As compared with the above emissions measurement methods, PEMS are able to obtain emissions data from vehicles operating in real-time on the field road network, taking into account the impact of changing traffic conditions.

Some researchers have studied emission characteristics based on PEMS to assess vehicle emissions better $[13,14]$. Still, as different vehicle loads have a critical role to play on the emissions of HDDTs [15,16], it is vital to explore the operating modes and emission characteristics of these trucks under varying loads. Yao et al. [17] tested the emissions of on-road HDDTs (with a gross vehicle weight of 16.0 tons) under $0 \%, 50 \%$, and $100 \%$ loads using PEMS. The results showed that emission factors of $\mathrm{NO}_{\mathrm{x}}$ and $\mathrm{PM}$ for the trucks when half-loaded were $43 \%$ and $59 \%$ higher than those obtained when the trucks were unloaded, and $62 \%$ and $44 \%$ higher when fully loaded. Elsewhere, Frey et al. [3] collected emissions data for diesel-fueled tandem trucks (with a gross vehicle weight of 29.0 tons) under different loads using PEMS and studied the emission variations between unloaded and fully loaded trucks. Their results indicated that the difference for loaded trucks versus unloaded trucks is $44 \%$ for $\mathrm{CO}_{2}, 78 \%$ for $\mathrm{NO}_{x}, 23 \%$ for $\mathrm{PM}, 30 \%$ for $\mathrm{HC}$ and $22 \%$ for $\mathrm{CO}$. Song et al. [18] obtained the emissions data of two HDDTs (with a gross vehicle weight of 25.0 tons) with different loads (empty, half, and full loads). This study found that the $\mathrm{NO}_{\mathrm{x}}, \mathrm{CO}$, and THC emission factors of the tested vehicles when half loaded and fully loaded were $18 \%$ to $41 \%, 6 \%$ to $67 \%$, and $37 \%$ to $125 \%$ higher than those obtained when the trucks were not loaded, respectively. During the field testing, it is challenging to maintain the same transport scenario for vehicles for different loads based on the PEMS test alone. Therefore, it is impossible to perform a comparable and consistent analysis for HDDTs emissions at various load states.

The vehicle specific power (VSP) distributions could be used to further characterize traffic conditions and vehicle emissions. The VSP or STP was designed to reflect the engine power required for the vehicle to overcome aerodynamic, rolling resistance, and rotational forces, so as to move the vehicle forward on the actual road [19]. Song et al. [20] characterized the VSP distribution of light-duty vehicles on urban restricted-access roadways and established a relationship between the VSP distribution and the average operating speed. Lai et al. [21] constructed a city-specific driving cycle based on the STP distribution for transit buses and then estimated vehicle emissions. Li et al. [22] established VSP binning division using field data for urban transit buses to better reflect these vehicles' operating characteristics. Zhang et al. [4] proposed a method for calculating the VSP values and developed an emissions model for heavy-duty refuse trucks (with a gross vehicle weight of 15.5 tons) to analyze the impact of empty and full loads on emissions.

It is only one-sided to consider the effect of changes in VSP distribution on the emissions of various loaded DSTTTs [23]. For DSTTTs equipped with a selective catalytic 
reduction (SCR) system, the exhaust temperature seriously affects the $\mathrm{NO}_{\mathrm{x}}$ emission rate [24]. The activity level the catalyst rises and then falls with activity level changes in exhaust temperature, resulting in the variations in the $\mathrm{NO}_{x}$ conversion efficiency $[25,26]$. The heavier vehicle load causes the NOx concentration at the inlet of the SCR device to increase, and at the same time, it also leads the exhaust temperature to rise. Under the simultaneous effects of these two factors, the ultimate $\mathrm{NO}_{\mathrm{x}}$ emission rate changes caused by various load conditions needs to be further analyzed.

Existing studies suggest that vehicle loads have a significant effect on the emissions of HDDTs. Most studies on HDDTs can be mainly divided into two categories, one is to analyze the emission characteristics directly based on the emission data, the other is to study the difference of VSP distribution based on the vehicle operation data. The studies based on emission data mainly uses the data collected by the engine dynamometer or PEMS. The former can hardly reflect the effect of truckloads on emissions in the real-world, and the latter approach does not ensure the accurate analysis of emissions for different load levels for the same traffic conditions. Meanwhile, a few VSP-based studies on HDDT emissions mainly concentrate on the influence of VSP distributions on emissions for different loaded trucks. It does not take into account the fluctuation of exhaust temperature, which affects the differences in emission rates corresponding to the VSP distributions. Besides, few studies have assessed the emission differences of DSTTTs with a wide load range.

In this context, the method for calculating the scaled tractive power (STP) and the emissions model for DSTTTs was developed based on second-by-second field speed data collected using on-board diagnostics (OBD) devices and emission data obtained by using PEMS instruments. Then, the operating modes and emission rates for DSTTTs were analyzed under various loads further to understand the effect of truck loads on emission factors. Finally, emission factor differences of $\mathrm{CO}_{2}, \mathrm{CO}, \mathrm{THC}$, and $\mathrm{NO}_{\mathrm{x}}$ under different load conditions were compared.

\section{Materials and Methods}

The methods adopted for this study consisted of five sections, as shown in Figure 1. First, emission data and the field operating data were acquired from 25 DSTTTs under different load conditions. The vehicle weights were approximately 14.5 tons for unloaded trucks, 49.0 tons for fully loaded trucks, and 61.5 tons for overloaded trucks. Second, the data processing methods of STP distribution and the emission rate model were designed. Third, the STP distribution in each speed bin of DSTTTs under different load states was compared and explained. Fourth, emission rate differences in $\mathrm{CO}_{2}, \mathrm{CO}, \mathrm{THC}$, and $\mathrm{NO}_{x}$ under various load states were analyzed. Finally, the emission factors of $\mathrm{CO}_{2}, \mathrm{CO}, \mathrm{THC}$, and $\mathrm{NO}_{\mathrm{x}}$ under various load states were modeled as a function of speed.

\subsection{Data Preparation}

\subsubsection{Data Collection and Tested Vehicles}

Due to the limitation of data acquisition conditions, vehicle data were obtained in two ways. One method was the acquisition of second-by-second activity data of the DSTTTs, which was used to study the operation difference between various load states under the same traffic modes; the other method was by gathering vehicle emissions data, which was used to establish an emission rate model to analyze the differences in emission rates among trucks with varying loads.

A total of 10 DSTTTs were identified in Shandong Province to gather second-bysecond operating speed data using OBD devices to study STP distribution characteristics for DSTTTs under different loads. The speed data collected for this study covered three conditions: unloaded, fully loaded, and overloaded. The payloads information of DSTTTs was obtained from a weighbridge prior to each test. The test vehicle information was listed in Table 1 . The gathered activity data included 1,692,632 records of second-by-second DSTTTs trajectories under the unloaded condition, 1,454,043 records under the fully loaded 
condition, and 452,502 records under the overloaded condition. Study data were collected from 28 March 2020, to 10 June 2020.

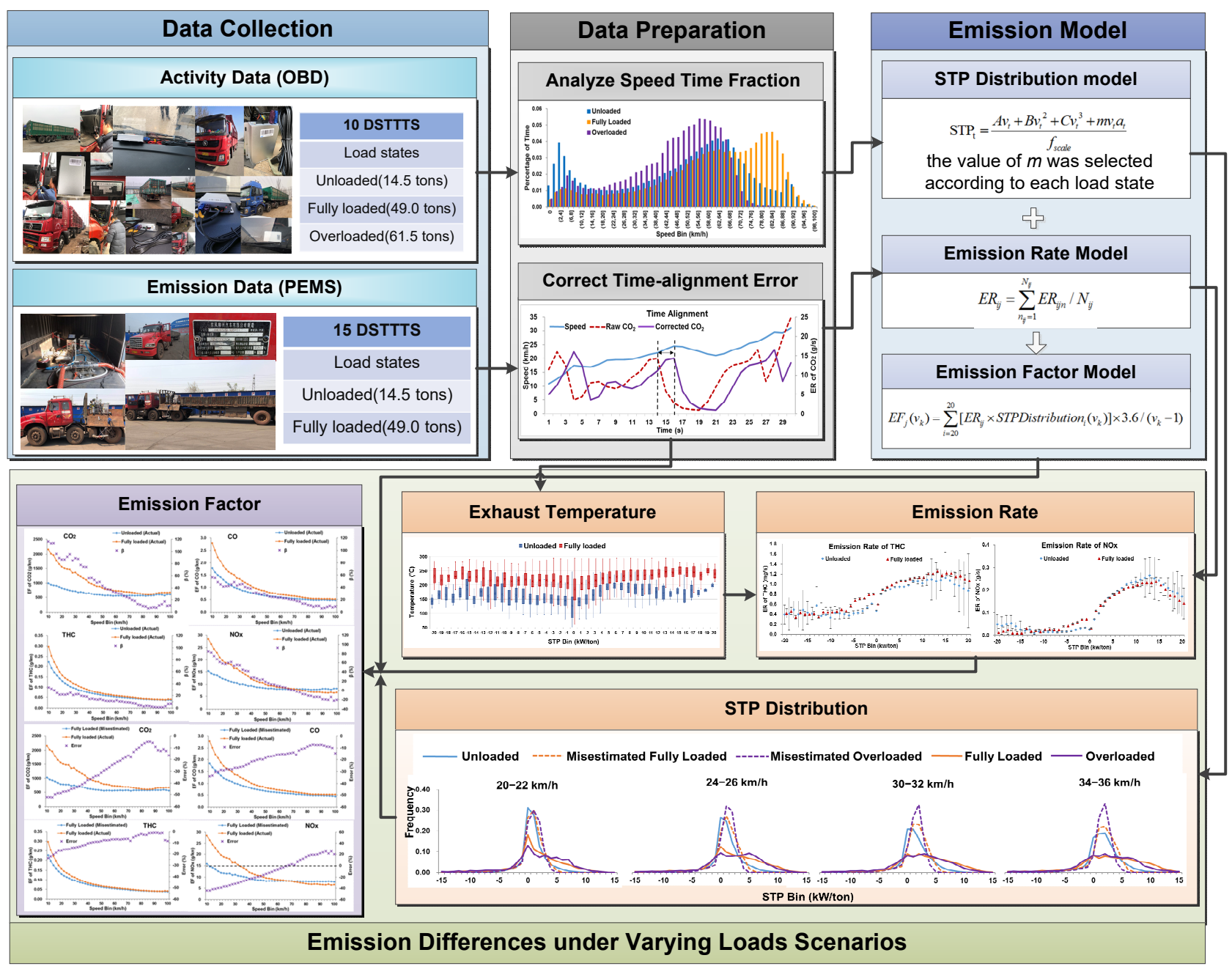

Figure 1. Framework of this study.

Meanwhile, truck emissions data were collected using a PEMS instrument (HORIBA OBS-ONE, Japan) from 23 August 2018 to 10 September 2018, in Heibei province. The emissions data collected covered the unloaded condition and fully loaded condition. The detailed information on DSTTTs used for emissions testing is provided in Table 2. The DSTTTs weights were roughly 14.5 tons for unloaded trucks and 49.0 tons for fully loaded vehicles. The quality control of the collected data was carried out through speed and acceleration. One was to eliminate data with a speed exceeding $120 \mathrm{~km} / \mathrm{h}$, and the other was to filter the data by using the $98 \%$ acceleration distribution quantile as the threshold. After rigorous data quality control procedures, a total of 153,215 valid second-by-second emissions data were retained, including 101,432 records for empty trucks and 51,783 records for fully loaded trucks. 
Table 1. Basic information about DSTTTs for speed data collection.

\begin{tabular}{|c|c|c|c|c|c|c|c|}
\hline Vehicle ID & Model & Fuel Type & Power (kW) & $\begin{array}{l}\text { Engine Size } \\
\text { (L) }\end{array}$ & $\begin{array}{l}\text { Curb Weight } \\
\text { (Tons) }\end{array}$ & $\begin{array}{l}\text { Gross Vehicle } \\
\text { Weight (Tons) }\end{array}$ & $\begin{array}{l}\text { Field Load } \\
\text { (Tons) }\end{array}$ \\
\hline 1 & SX4250MB4 & diesel & 276 & 9.5 & 8.6 & 40.0 & $14.5 / 49.0 / 61.5$ \\
\hline 2 & SX4250MB4 & diesel & 276 & 11.6 & 8.6 & 40.0 & $14.5 / 49.0 / 61.5$ \\
\hline 3 & BJ4252SNFKB-XA & diesel & 257 & 10.5 & 7.3 & 38.5 & $14.5 / 49.0 / 61.5$ \\
\hline 4 & BJ4253SNFKB-XJ & diesel & 279 & 11.8 & 7.3 & 38.5 & $14.5 / 49.0 / 61.5$ \\
\hline 5 & LZ4240H7CA & diesel & 316 & 11.6 & 7.3 & 38.5 & $14.5 / 49.0 / 61.5$ \\
\hline 6 & C4250P66K2471A1E5 & diesel & 342 & 11.0 & 8.8 & 40.0 & $14.5 / 49.0 / 61.5$ \\
\hline 7 & CGC4252D4XBA & diesel & 316 & 11.6 & 8.0 & 37.8 & $14.5 / 49.0 / 61.5$ \\
\hline 8 & CGC4250D5EDDE & diesel & 316 & 11.6 & 8.8 & 40.0 & $14.5 / 49.0 / 61.5$ \\
\hline 9 & SX4250MC4 & diesel & 294 & 9.5 & 8.6 & 40.0 & $14.5 / 49.0$ \\
\hline 10 & GX4256GR129 & diesel & 247 & 9.7 & 7.2 & 38.6 & $14.5 / 49.0 / 61.5$ \\
\hline
\end{tabular}

Table 2. The parameters of DSTTTs for emission data collection.

\begin{tabular}{|c|c|c|c|c|c|c|c|c|c|}
\hline ID & VIN & $\begin{array}{l}\text { Vehicle } \\
\text { Model }\end{array}$ & $\begin{array}{l}\text { Model } \\
\text { Year }\end{array}$ & $\begin{array}{l}\text { Fuel } \\
\text { Type }\end{array}$ & $\begin{array}{l}\text { Emission } \\
\text { Standard }\end{array}$ & $\begin{array}{c}\text { Power } \\
(\mathbf{k W})\end{array}$ & $\begin{array}{l}\text { Engine } \\
\text { Size (L) }\end{array}$ & $\begin{array}{c}\text { Test Date } \\
\text { (Day/Month/Year) }\end{array}$ & $\begin{array}{l}\text { Field Load } \\
\quad \text { (tons) }\end{array}$ \\
\hline 1 & LGGA40X36GL ${ }^{* * * 447}$ & LZ4230G2CA & 2016 & diesel & National 4 & 226 & 9.7 & $23 / 08 / 2018$ & $14.5 / 49.0$ \\
\hline 2 & LGGA4DX31GL ${ }^{* * * 240}$ & LZ4230G2CA & 2016 & diesel & National 4 & 226 & 9.7 & $24 / 08 / 2018$ & $14.5 / 49.0$ \\
\hline 3 & LGGA4DX32GL ${ }^{* * * 621 ~}$ & LZ4230G2CA & 2016 & diesel & National 4 & 226 & 9.7 & $25 / 08 / 2018$ & 14.5 \\
\hline 4 & LGGA4DX32GL ${ }^{* * * 451}$ & LZ4230G2CA & 2016 & diesel & National 4 & 226 & 9.7 & $27 / 08 / 2018$ & $14.5 / 49.0$ \\
\hline 5 & LGGA4DX33GL ${ }^{* * *} 132$ & LZ4230G2CA & 2016 & diesel & National 4 & 226 & 9.7 & $28 / 08 / 2018$ & 14.5 \\
\hline 6 & LGGA4DX34GL ${ }^{* * *} 460$ & LZ4230G2CA & 2016 & diesel & National 4 & 226 & 9.7 & $29 / 08 / 2018$ & 14.5 \\
\hline 7 & LGGA4DX34GL ${ }^{* * * 670}$ & LZ4230G2CA & 2016 & diesel & National 4 & 226 & 9.7 & $30 / 08 / 2018$ & $14.5 / 49.0$ \\
\hline 8 & LGGA4DX34GL ${ }^{* * * 298}$ & LZ4230G2CA & 2016 & diesel & National 4 & 226 & 9.7 & $31 / 08 / 2018$ & 14.5 \\
\hline 9 & LGGA4DX34GL ${ }^{* * * 387}$ & LZ4230G2CA & 2016 & diesel & National 4 & 226 & 9.7 & $03 / 09 / 2018$ & 14.5 \\
\hline 10 & LGGA4DX34GL**435 & LZ4230G2CA & 2016 & diesel & National 4 & 226 & 9.7 & $04 / 09 / 2018$ & 14.5 \\
\hline 11 & LGGA4DX34GL**525 & LZ4230G2CA & 2016 & diesel & National 4 & 226 & 9.7 & $04 / 09 / 2018$ & 14.5 \\
\hline 12 & LGGA4DX36GL ${ }^{* * * 383 ~}$ & LZ4230G2CA & 2016 & diesel & National 4 & 226 & 9.7 & $04 / 09 / 2018$ & $14.5 / 49.0$ \\
\hline 13 & LGGA4DX39GL ${ }^{* * * 003}$ & LZ4230G2CA & 2016 & diesel & National 4 & 226 & 9.7 & $07 / 09 / 2018$ & $14.5 / 49.0$ \\
\hline 14 & LGGA4DX3XGL ${ }^{* * * 460}$ & LZ4230G2CA & 2016 & diesel & National 4 & 226 & 9.7 & $10 / 09 / 2018$ & 14.5 \\
\hline 15 & LGGA4DX3XGL $* * * 543$ & LZ4230G2CA & 2016 & diesel & National 4 & 226 & 9.7 & $10 / 09 / 2018$ & 14.5 \\
\hline
\end{tabular}

\subsubsection{Data Preparation}

After controlling for data quality, the interval of $2 \mathrm{~km} / \mathrm{h}$ was used to divide the speed bin and the time proportion of samples in each speed interval analyzed. As shown in Figure 2, the average speeds of unloaded, fully loaded, and overloaded trucks were $48.68 \mathrm{~km} / \mathrm{h}, 60.45 \mathrm{~km} / \mathrm{h}$, and $45.39 \mathrm{~km} / \mathrm{h}$, respectively. The speed distribution of unloaded trucks was more scattered and the time proportion of samples in each speed bin below $92 \mathrm{~km} / \mathrm{h}$ exceeded $1 \%$. There were three peaks in the speed distribution for the unloaded trucks, which were 2 to $4 \mathrm{~km} / \mathrm{h}, 62$ to $64 \mathrm{~km} / \mathrm{h}$, and 88 to $90 \mathrm{~km} / \mathrm{h}$, respectively. This speed distribution could be explained by the idea that trucks queuing up to load in a logistics park led to long-term low-speed operation, while unloaded vehicles typically use unrestricted access roads to get to closer loading points, resulting in vehicles in medium speed operation, or using restricted access roads to return from further destinations after unloading to make them operating at a relatively high speed. Fully loaded trucks operated mainly in the speed ranges of 58 to $88 \mathrm{~km} / \mathrm{h}$. This situation is likely because the trucks reached their destination via the restricted access roads after loading cargo. Finally, the speed data of overloaded trucks were more concentrated than those with the no-load and a full load. The overloaded vehicles mainly operated in the speed range of 42 to $66 \mathrm{~km} / \mathrm{h}$ and there was relatively limited operation data available in the high-speed range. These trucks typically drive on unrestricted-access roads to avoid administrative penalties and, due to vehicle performance limitations and driver safety considerations, the operating speed of such overloaded trucks was relatively low. 


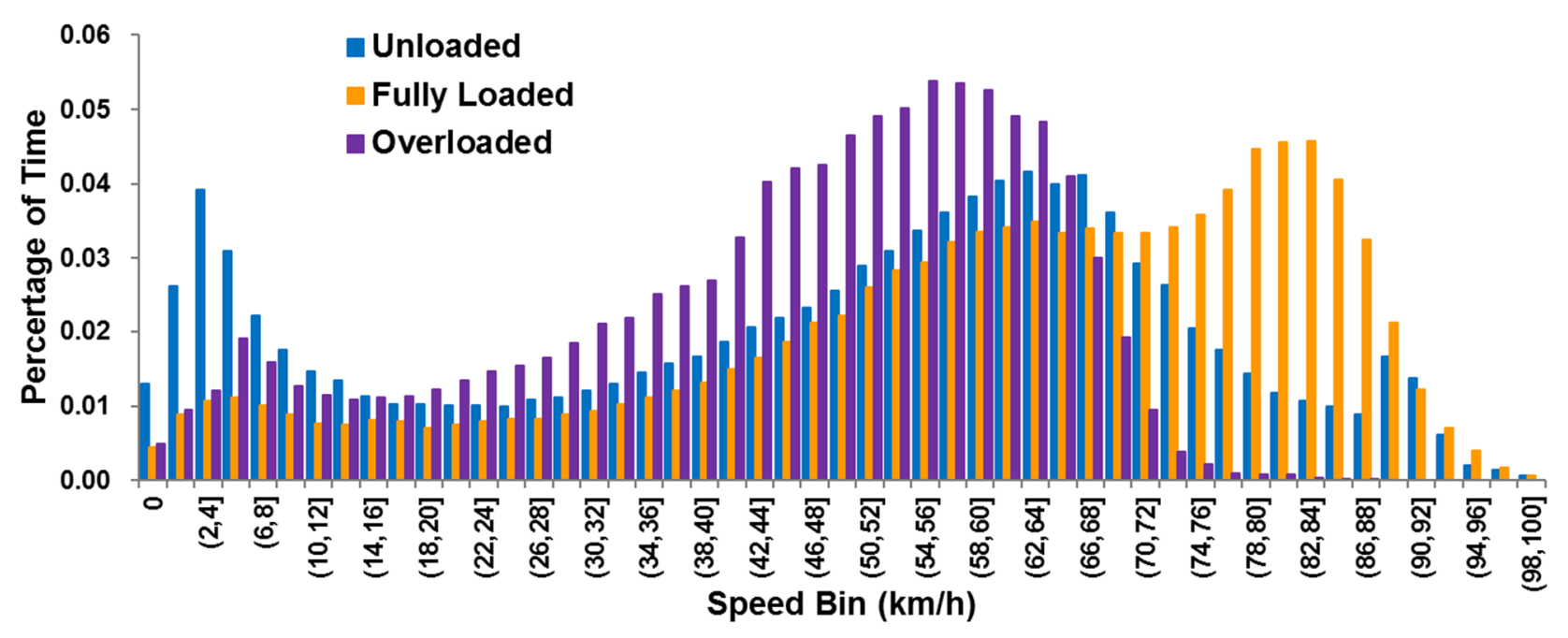

Figure 2. Time percentage of operating speed for trucks under unloaded, fully loaded and overloaded states in each speed bin.

A time-alignment error typically existed in data streams from the exhaust gas collection system and the global positioning system or OBD devices' speed recorder. In this study, different data sources were used to calculate STP and emission rates and there was a time lag reflecting different operating modes of the vehicle at the same time. For example, in Figure 3, the $\mathrm{CO}_{2}$ emission data of trucks lagged the operating speed at the same time. This study presumed that the time of the STP was considered as the basic timeline in the calibration method. Then, the time alignment sequence was readjusted based on the maximum correlation coefficient between the STP and emission data. It should be emphasized that the various pollutants must be modified individually with operating speed due to discrepancies in time-alignment errors for different pollutants. The consistency of $\mathrm{CO}_{2}, \mathrm{CO}, \mathrm{THC}, \mathrm{NO}_{\mathrm{x}}$ and STP values were significantly improved following correction for time-alignment error.

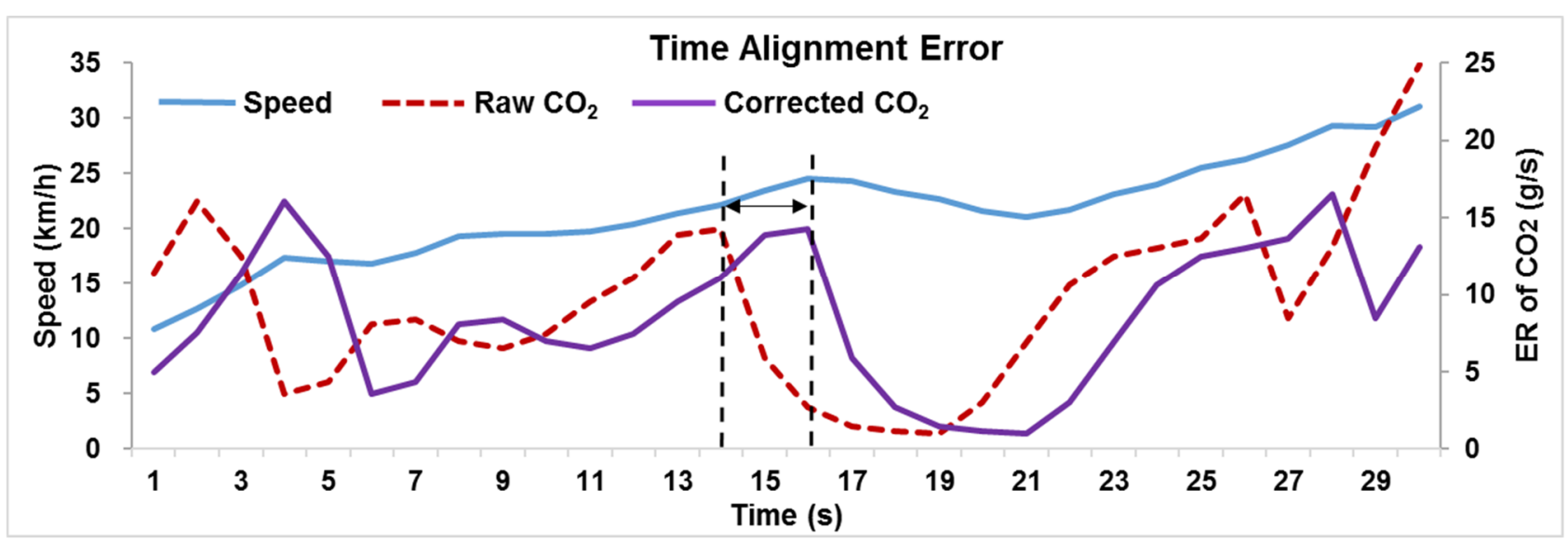

Figure 3. Time alignment error of $\mathrm{CO}_{2}$ emission data steam.

\subsection{Calculation of STP Distribution and Emission Rate}

To avoid the impact of road slope on the analysis of truck activity loads, sloped roads, both uphill and downhill with slopes exceeding $1.5 \%$, were marked during the data quality control process. These tagged data were then excluded when performing data analysis to 
calculate STP values. The formula was calculated using Equation (1) as follows without the parameter of road gradient:

$$
\mathrm{STP}_{\mathrm{t}}=\frac{A v_{t}+B v_{t}^{2}+C v_{t}^{3}+m v_{t} a_{t}}{f_{\text {scale }}}
$$

where $\mathrm{STP}_{\mathrm{t}}=\mathrm{STP}$ value at time $t(\mathrm{~kW} / \mathrm{ton}), v_{t}=$ operating speed at time $t(\mathrm{~m} / \mathrm{s}), a_{t}=$ transient acceleration of truck operation at time $t\left(\mathrm{~m} / \mathrm{s}^{2}\right), m=$ gross truck weight (tons), $A=$ rolling resistance coefficient $(\mathrm{kW}-\mathrm{s} / \mathrm{m}), B=$ rotational resistance coefficient $\left(\mathrm{kW}-\mathrm{s}^{2} / \mathrm{m}^{2}\right), C=$ aerodynamic drag coefficient $\left(\mathrm{kW}-\mathrm{s}^{3} / \mathrm{m}^{3}\right)$, and $f_{\text {scale }}=$ scaling factor, with a fixed value of 17.1 being suggested [27].

As shown in Equation (1), the A, B, and C were constant for a specific vehicle type. Moreover, the speed, acceleration, and gross vehicle weight determined its calculated STP values. Therefore, for the same operation mode, an increase of $\mathrm{m}$ led to a proportional increase in STP values. In this study, the values of $m$ used for calculating STP values for DSTTTs that were unloaded, fully loaded, and overloaded were 14.5 tons, 49.0 tons, and 61.5 tons, respectively. The method for obtaining the STP distribution and emission rates under different loads was as follows:

(1) Calculating second-by-second STP values of trucks under unloaded, fully loaded, and overloaded conditions using Equation (1) where the value of $\mathrm{m}$ was selected according to each load state.

(2) Clustering STP values to obtain the STP Bins, and those values were divided into various bins defining the equivalent interval as $1 \mathrm{~kW} /$ ton, as shown in Equation (2):

$$
\forall: \mathrm{STP}_{\mathrm{t}} \in[n-0.5, n+0.5] ; \operatorname{STP} \operatorname{Bin} \#=n ; n \in[-20,20]
$$

where STP Bin \# = ID of the STP pool, and $n=$ an integer

Obtaining STP distributions by computing the time percentage in each STP bin within a defined speed interval for unloaded, fully loaded, and overloaded trucks. The continuous speed data were divided into trajectories, each consisting of 60 consecutive seconds of operating data. The average speed was calculated for each trajectory using Equation (3). Then, the trajectories were put into trajectory pools with specific speeds based on their average speed. Meanwhile, the specific-speed trajectory pool was defined by the speed bin with an equal spacing of $2 \mathrm{~km} / \mathrm{h}$, as shown in Equation (4):

$$
\begin{gathered}
\text { average speed }=3.6 \cdot \sum_{i=1}^{60} v_{i} / 60 \\
\forall: \text { average speed } \in(n-2, n] ; \text { Speed Bin\# }=n
\end{gathered}
$$

The mean and standard deviation were calculated separately for each pollutant in the STP Bin. The mean value plus and minus three times the standard deviation was used as the threshold value within each STP bin to ensure that the second-by-second emission rate data were within the corresponding threshold values. After removing abnormal data, the average emission value in each STP bin was taken as the pollutant's emission rate. The average emission rate was calculated using Equation (5) as follows:

$$
E R_{i j}=\sum_{n_{i j}=1}^{N_{i j}} E R_{i j n} / N_{i j}
$$

where $E R_{i j}=$ average emission rate of emission $i$ in STP bin $j(\mathrm{~g} / \mathrm{s}), E R_{i j n}=$ the $n$-th measured value of emission $i$ in STP bin $j(\mathrm{~g} / \mathrm{s})$, and $N_{i j}=$ the amount of data of emission $i$ in STP bin $j$. 


\subsection{The Calculation Method of Emission Factor Based on STP Distribution and Emission Rate}

To contrast and characterize differences in emissions of DSTTTs under varied loads further, emission factors for trucks with different load states were calculated. First, the STP distribution in each speed bin was used to describe driving behaviors based on field operation data. Then, emission rates for different load states in STP bins were calculated according to collected emission data. Finally, taking STP as the intermediate parameter, the STP distribution and emission rate were integrated to calculate emission factors for different loaded trucks at different speed intervals using Equation (6):

$$
E F_{j}\left(v_{k}\right)=\sum_{i=-20}^{20}\left[\operatorname{ER}_{i j} \times \operatorname{STPDistribution}_{i}\left(v_{k}\right)\right] \times 3.6 /\left(v_{k}-1\right)
$$

where $E F_{j}\left(v_{k}\right)=$ the emission factor of $j$ for trucks at the speed interval of $v_{k}(\mathrm{~g} / \mathrm{km})$, $E R_{i j}=$ the emission rate of $j$ for trucks at the STP bin of $i(\mathrm{~g} / \mathrm{s}), \operatorname{STPDistribution}\left(v_{k}\right)=$ the percentage of STP Bin of $i$ for trucks at the speed interval of $v_{k}(\%)$, and $v_{k}=$ the speed bin $(\mathrm{m} / \mathrm{s})$.

\section{Results and Discussion}

\subsection{STP Characteristics for DSTTTs under Different Load States}

The STP distribution is the percentage of time that the vehicle spends in each STP bin during operation, representing the power needed for a given operating mode. To analyze the STP distribution characteristics of DSTTTs under various loading states, 12 speed ranges were selected for analysis, which were 20 to $22 \mathrm{~km} / \mathrm{h}, 24$ to $26 \mathrm{~km} / \mathrm{h}, 30$ to $32 \mathrm{~km} / \mathrm{h}, 34$ to $36 \mathrm{~km} / \mathrm{h}, 40$ to $42 \mathrm{~km} / \mathrm{h}, 44$ to $46 \mathrm{~km} / \mathrm{h}, 50$ to $52 \mathrm{~km} / \mathrm{h}, 54$ to $56 \mathrm{~km} / \mathrm{h}, 60$ to $62 \mathrm{~km} / \mathrm{h}, 64$ to $66 \mathrm{~km} / \mathrm{h}, 70$ to $72 \mathrm{~km} / \mathrm{h}$, and 74 to $76 \mathrm{~km} / \mathrm{h}$, respectively, as shown in Figure 4 . However, it was difficult to obtain real-time load information of trucks on the road network when evaluating the emissions of road network trucks, which led to mistaking fully loaded and overloaded trucks as empty. In most cases, the STP distribution of the truck under fully loaded and overloaded conditions was calculated according to the unloaded truck weight. This study also analyzed the STP distribution characteristics when the fully loaded or overloaded trucks were mistaken as the unloaded state, as shown in Figure 4.

STP distributions at speed intervals under different load statuses were also illustrated in Figure 4, and the characteristics could be summarized as follows:

(1) STP distributions within all the speed intervals were shaped like a Gaussian distribution, regardless of load state. Under the same load condition, the STP distribution was more cramped as the speed increased. The STP distributions of fully loaded and overloaded conditions obtained from the actual vehicle weight were quite different from those obtained from the unloaded vehicle weight.

(2) When the STP distribution was studied according to the actual vehicle weight, the STP distribution under the unloaded state was more concentrated than that under the fully loaded or overloaded state. The lower part of the Gaussian distribution for fully loaded and overloaded trucks was significantly wider than that for trucks with an unloaded state. The peak value of the STP distribution within the unloaded state was significantly higher than that of the fully loaded or overloaded state. In speed intervals of less than $32 \mathrm{~km} / \mathrm{h}$, the STP distribution percentages of full load and overload were greater than those of the load in the higher bins. Meanwhile, in the speed intervals greater than $34 \mathrm{~km} / \mathrm{h}$, the percentages of STP distributions for fully loaded and overloaded were greater than those for the unloaded condition in both the higher and lower bins. Besides, the STP distribution of the overloaded state was more cramped than that for the fully loaded state, especially when the speed was greater than $64 \mathrm{~km} / \mathrm{h}$.

(3) When the STP distribution was analyzed according to the unloaded truck weight under the conditions of fully loaded and overloaded, the STP distributions were more concentrated as the truck load increased in the same speed interval. This was mainly 
because as the load increases the acceleration and deceleration performance of the vehicle became worse, making the acceleration distribution more concentrated, as shown in Figure 5. In addition, the peak value of STP distribution shifted to the right as the average speed increased. At the speed intervals of less than $32 \mathrm{~km} / \mathrm{h}$, the bins with the highest percentage of STP distributions for the empty, full load, and overload conditions were different and the distributions of full load and overload were shifted more to the right. The highest percentage of STP distributions for empty, full load, and overload conditions were within the same bins in the speed intervals analyzed for speeds of greater than $34 \mathrm{~km} / \mathrm{h}$.

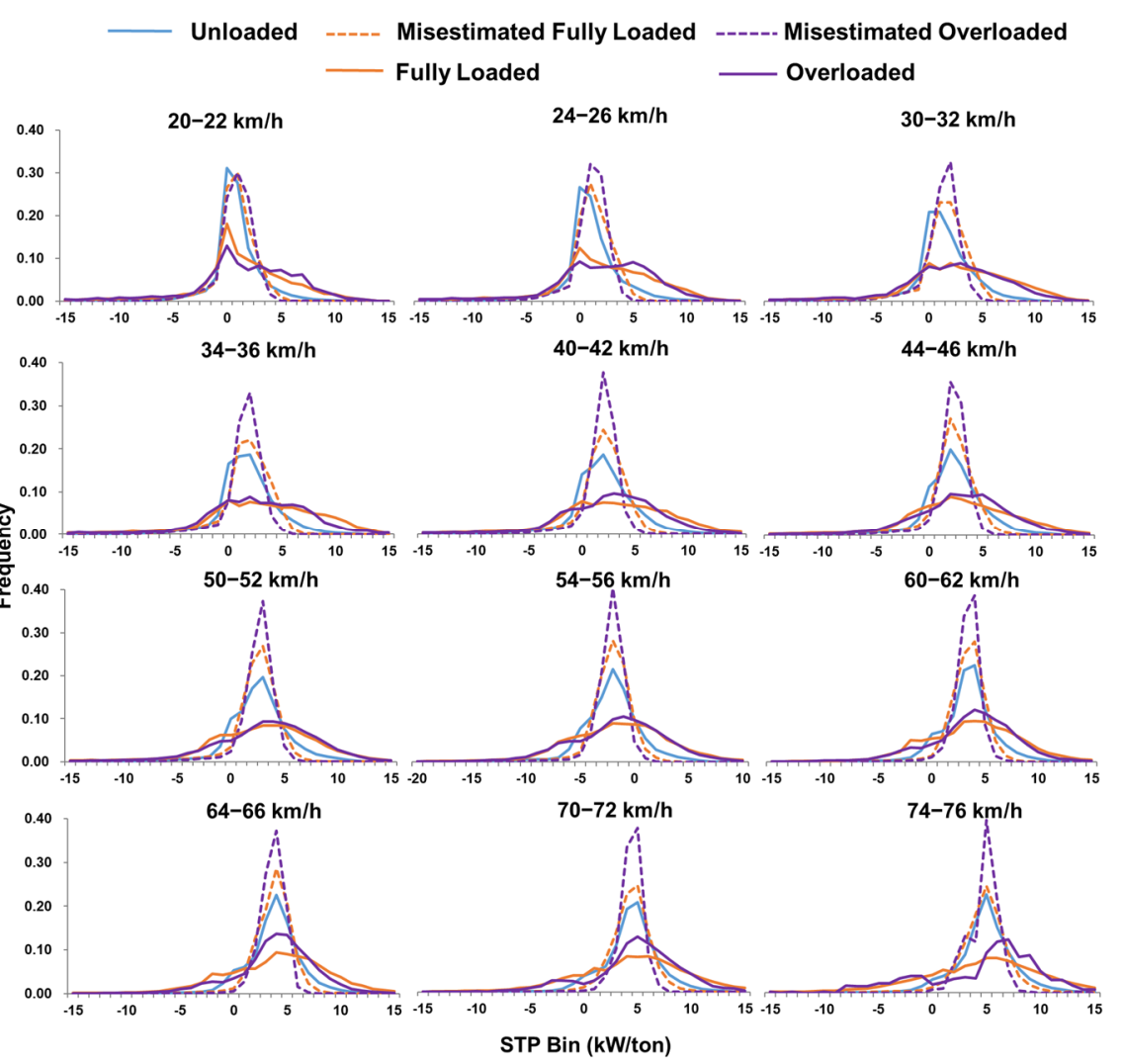

Figure 4. STP distribution for DSTTTs with unloaded, fully loaded and overloaded in different speed bins (unloaded, $\mathrm{m}=14.5$ tons; misestimated fully loaded, $m=14.5$ tons; misestimated overloaded, $m=14.5$ tons; fully loaded, $m=49.0$ tons; overloaded, $\mathrm{m}=61.5$ tons).

\subsection{Emission Rate Analysis of Different Load States}

The emission rate model is an essential tool that can be used in conjunction with vehicle activity data to assess the effect of traffic-control strategies on emissions. One significant factor that affects the accuracy of emissions assessments is the difference in vehicle emission rates under various vehicle load conditions. Therefore, this study collected emission data of $\mathrm{CO}_{2}, \mathrm{CO}, \mathrm{THC}$, and $\mathrm{NO}_{\mathrm{x}}$ for 15 unloaded and fully loaded DSTTTs. Due to the limitations of collection conditions, the emissions data of overloaded vehicles could not be obtained. In this study, the emission differences between unloaded and fully loaded vehicles in each bin were compared, as shown in Figure 6. To quantify emission discrepancies between fully loaded and empty trucks, a parameter $\alpha$ representing the relative difference in emission rates between fully loaded and unloaded DSTTTs was defined in Equation (7), while the differences of $\alpha$ in emission rates between empty and fully loaded trucks are shown in Table 3:

$$
\alpha_{i j}=\frac{E R_{\text {fullyloaded }-i j}-E R_{\text {unloaded }-i j}}{E R_{\text {fullyloaded }-i j}} \times 100 \%
$$


where, $\alpha_{i j}=$ the relative difference of $j$ emission rates between fully loaded and unloaded DSTTTs in the STP Bin $i(\%), E R_{\text {fullyloaded }-i j}=$ the $j$ emission rate of DSTTTS under fully loaded status in the STP bin of $i(\mathrm{~g} / \mathrm{s})$, and $E R_{\text {unloaded-ij }}=$ the $j$ emission rate of the truck under unloaded status in the STP $\sin$ of $i(\mathrm{~g} / \mathrm{s})$.

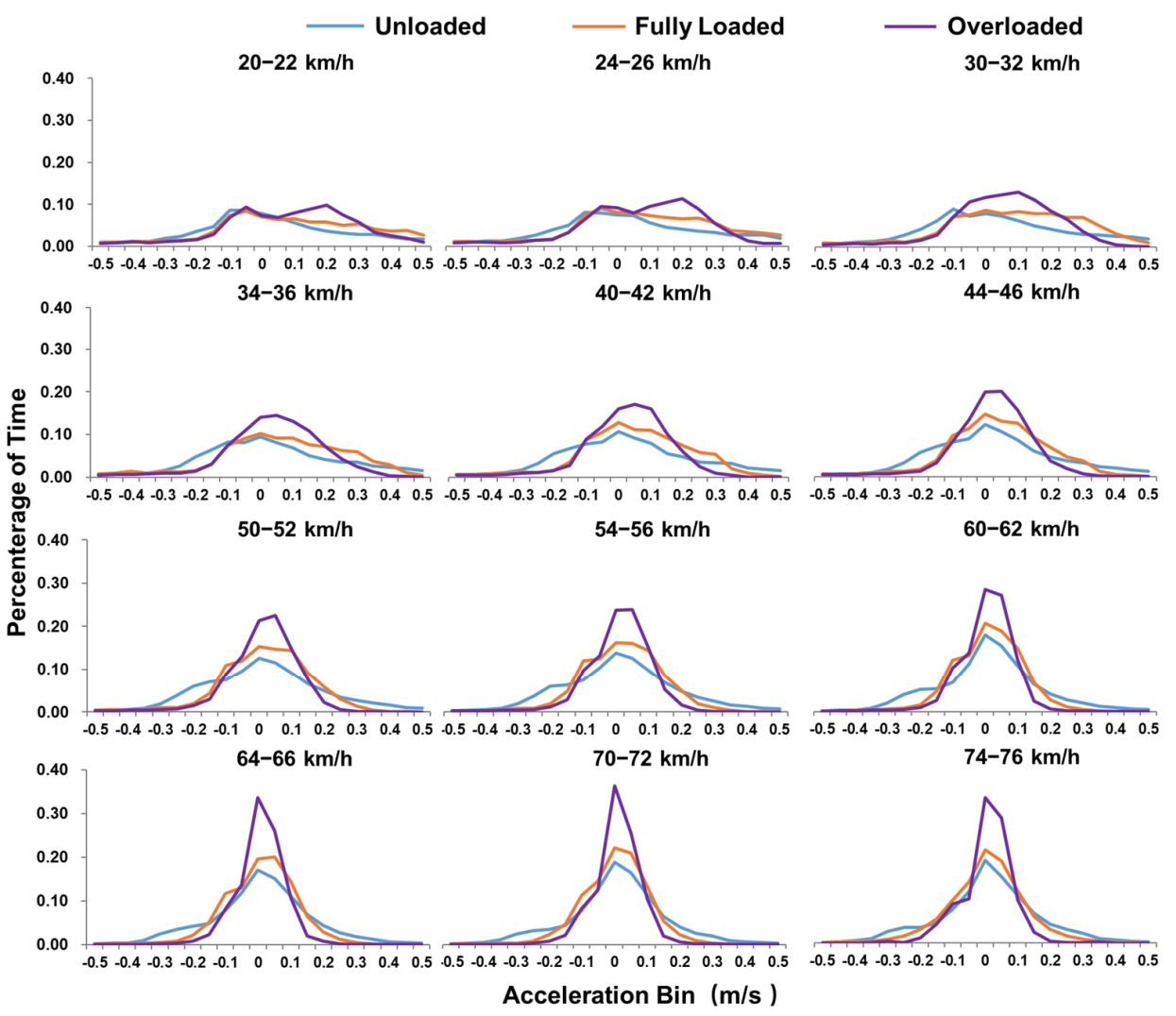

Figure 5. Acceleration distribution for DSTTTs with unloaded, fully loaded and overloaded in different speed bins.
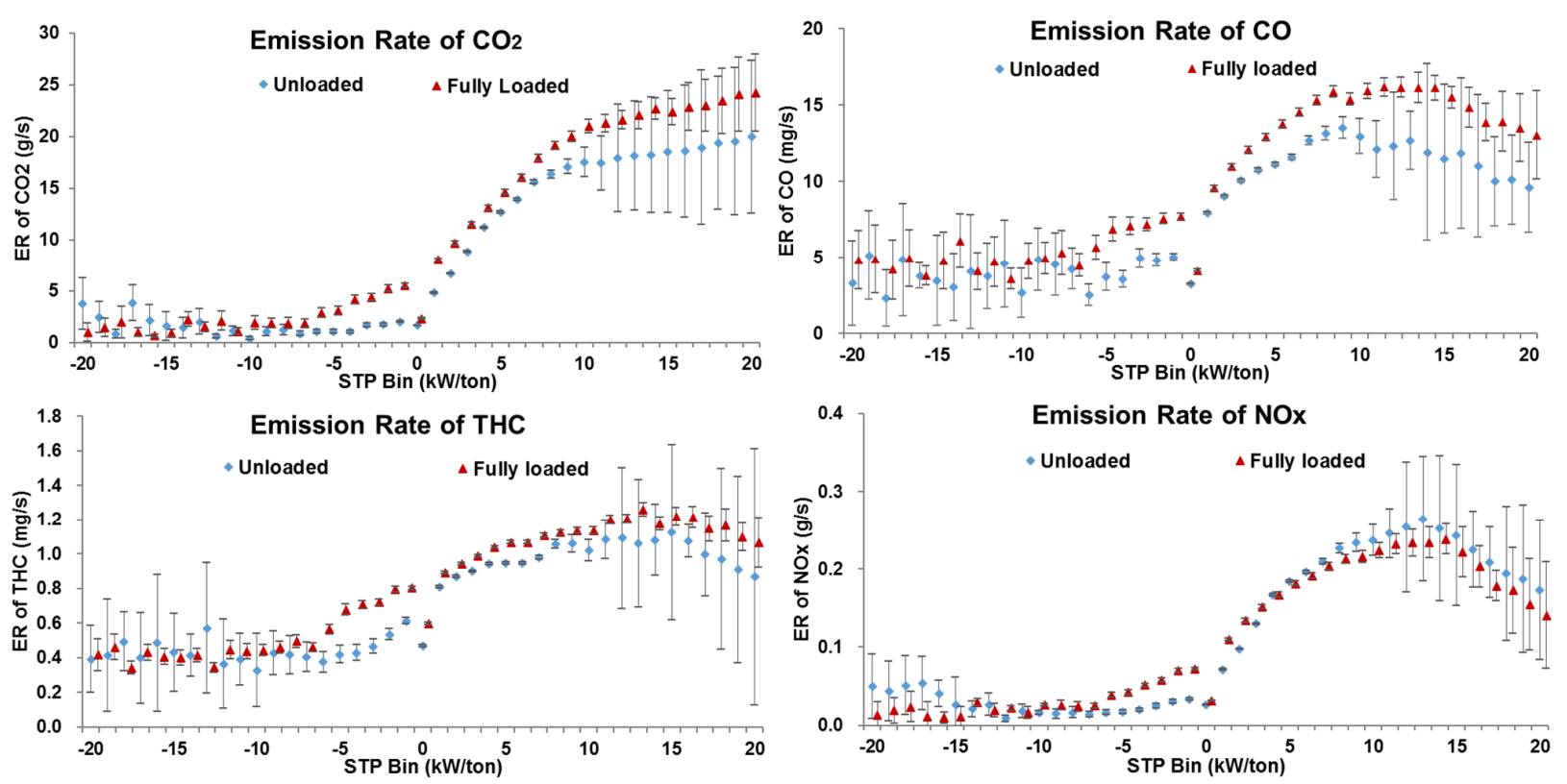

Figure 6. Emission rates of $\mathrm{CO}_{2}, \mathrm{CO}, \mathrm{THC}$ and $\mathrm{NO}_{x}$ for DSTTTs with unloaded and fully loaded in STP bins. (with $95 \%$ confidence intervals). 
According to Figure 6 and Table 3, the characteristics of the emission rate difference of trucks under unloaded and fully loaded conditions could be expounded as follows:

(1) When the STP bin was less $0 \mathrm{~kW} /$ ton, the emission rate differences of $\mathrm{CO}_{2}, \mathrm{CO}, \mathrm{THC}$, and $\mathrm{NO}_{\mathrm{x}}$ between the fully loaded and unloaded trucks were consistent between pollutants. When the STP bin was $-11 \mathrm{~kW} /$ ton or less, each pollutant's emission rate was relatively low, and $\alpha$ shows positive and negative values. When the STP bin was between $-10 \mathrm{~kW} /$ ton and $-1 \mathrm{~kW} /$ ton, the emission rates of the DSTTTs in the fully loaded state in each bin were significantly higher than those in the unloaded state, especially when the STP bin was $-5 \mathrm{~kW} /$ ton or greater. When the STP bin was between $-5 \mathrm{~kW} /$ ton and $-1 \mathrm{~kW} /$ ton, the average values of $\alpha$ for $\mathrm{CO}_{2}, \mathrm{CO}, \mathrm{THC}$, and $\mathrm{NO}_{\mathrm{x}}$ were $209.9 \%, 67.7 \%, 52.6 \%$, and $137.3 \%$, respectively.

(2) When the STP bin was $0 \mathrm{~kW} /$ ton or greater, the emission rates of $\mathrm{CO}_{2}, \mathrm{CO}, \mathrm{THC}$, and $\mathrm{NO}_{x}$ showed diverse trends together with bins increases. With increases in the STP bin, the $\mathrm{CO}_{2}$ emission rates of trucks in fully loaded and unloaded states showed a rapid increase and then the growth rate slowed down. In each bin, the $\mathrm{CO}_{2}$ emission rate of fully loaded DSTTTS was higher than that of unloaded. The average values of $\alpha$ were $27.6 \%$ and $22.0 \%$ when the STP bin was between $0 \mathrm{~kW} /$ ton and $10 \mathrm{~kW} /$ ton and between $11 \mathrm{~kW} /$ ton and $20 \mathrm{~kW} /$ ton, respectively.

(3) When the STP bin was $0 \mathrm{~kW} /$ ton or greater, the CO emission rates of vehicles in fully loaded and unloaded states showed a rapid increase but then a decrease increasing STP bin. In each bin, the CO emission rate of fully loaded DSTTTS was higher than of unloaded vehicles. The average values of $\alpha$ were $21.0 \%$ and $32.2 \%$ when the STP bin was between $0 \mathrm{~kW} /$ ton and $10 \mathrm{~kW} /$ ton and between $11 \mathrm{~kW} /$ ton and $20 \mathrm{~kW} /$ ton, respectively.

(4) When the STP bin was $0 \mathrm{~kW} /$ ton or greater, the THC emission rates of fully loaded and unloaded vehicles showed the trend of increasing first and then decreasing slightly as the STP bin increased. In each bin, the THC emission rate of fully loaded DSTTTs was higher than that of unloaded DSTTTs. The average values of $\alpha$ were $12.2 \%$ and $15.1 \%$ when the STP bin was between $0 \mathrm{~kW} /$ ton and $10 \mathrm{~kW} /$ ton and between $11 \mathrm{~kW} /$ ton and $20 \mathrm{~kW} /$ ton, respectively.

(5) Finally, when was $0 \mathrm{~kW} /$ ton or greater, the $\mathrm{NO}_{\mathrm{x}}$ emission rates of fully loaded and unloaded vehicles displayed the trend of increasing first and then decreasing sharply as the STP bin increased. When the STP bin was between $0 \mathrm{~kW} /$ ton and $3 \mathrm{~kW} /$ ton, the $\mathrm{NO}_{\mathrm{x}}$ emission rate of fully loaded DSTTTs was higher than that of unloaded trucks and the average value of $\alpha$ was $31.3 \%$. However, when the STP bin was $4 \mathrm{~kW} /$ ton or greater, the $\mathrm{NO}_{\mathrm{x}}$ emission rate of a fully loaded DSTTTS was lower than that of an unloaded vehicle. The absolute value of $\alpha$ increased gradually with increasing STP bin, and the average value of $\alpha$ was $-8.6 \%$. To further analyze the reasons for this variation in $\mathrm{NO}_{\mathrm{x}}$ emission rate, this study investigated the difference in vehicle exhaust temperature between unloaded and fully loaded conditions. For DSTTTs equipped with an SCR system, the exhaust temperature was an important factor affecting $\mathrm{NO}_{\mathrm{x}}$ conversion efficiency. For instances where SCR uses vanadia as a catalyst, the $\mathrm{NO}_{\mathrm{x}}$ conversion efficiency gradually increases with increasing temperature when the exhaust temperature is lower than $350^{\circ} \mathrm{C}[25,26]$. As shown in Figure 7, the exhaust temperature of DSTTTs in the fully loaded state was significantly higher than that of those in an unloaded state, which was why the $\mathrm{NO}_{\mathrm{x}}$ emission rate of vehicles in the fully loaded state was lower than that in the unloaded state. 
Table 3. The difference in emission rate under different loading conditions.

\begin{tabular}{|c|c|c|c|c|}
\hline \multirow{2}{*}{ STP Bin } & \multicolumn{4}{|c|}{$\alpha(\%)$} \\
\hline & $\mathrm{CO}_{2}$ & $\mathrm{CO}$ & $\mathrm{HC}$ & $\mathrm{NO}_{x}$ \\
\hline-20 & -74.0 & 46.1 & 6.4 & -75.0 \\
\hline-19 & -41.8 & -4.6 & 12.0 & -56.7 \\
\hline-18 & 135.5 & 80.0 & -30.4 & -54.1 \\
\hline-17 & -74.5 & 2.3 & 8.6 & -79.4 \\
\hline-16 & -70.3 & 0.5 & -16.0 & -76.8 \\
\hline-15 & -41.8 & 37.7 & -6.7 & -56.9 \\
\hline-14 & 59.4 & 99.4 & 0.6 & 41.3 \\
\hline-13 & -26.1 & 0.8 & -39.6 & -27.8 \\
\hline-12 & 262.8 & 24.9 & 22.2 & 151.6 \\
\hline-11 & -1.7 & -21.5 & 11.9 & -12.5 \\
\hline-10 & 391.3 & 79.2 & 35.4 & 65.6 \\
\hline-9 & 75.3 & 1.5 & 8.1 & 76.0 \\
\hline-8 & 55.3 & 16.8 & 19.2 & 45.0 \\
\hline-7 & 116.3 & 5.1 & 13.8 & 79.0 \\
\hline-6 & 181.3 & 126.9 & 50.6 & 140.1 \\
\hline-5 & 186.2 & 85.4 & 62.0 & 150.7 \\
\hline-4 & 312.1 & 98. & 65.5 & 158.1 \\
\hline-3 & 166.9 & 45.6 & 55.2 & 130.4 \\
\hline-2 & 205.3 & 56.5 & 49.1 & 132.7 \\
\hline-1 & 178.9 & 52.6 & 31.4 & 114.5 \\
\hline 0 & 42.3 & 27.4 & 27.8 & 19.6 \\
\hline 1 & 68.1 & 20.9 & 10.7 & 53.0 \\
\hline 2 & 46.0 & 21.9 & 8.6 & 36.8 \\
\hline 3 & 30.1 & 20.1 & 10.3 & 15.8 \\
\hline 4 & 17.2 & 20.3 & 10.5 & -0.4 \\
\hline 5 & 15.3 & 23.8 & 13.2 & -2.0 \\
\hline 6 & 15.6 & 25.1 & 13.1 & -3.1 \\
\hline 7 & 15.1 & 20.8 & 13.6 & -3.4 \\
\hline 8 & 14.3 & 20.8 & 6.7 & -6.7 \\
\hline 9 & 15.5 & 13.7 & 7.6 & -8.6 \\
\hline 10 & 19.6 & 22.8 & 11.9 & -5.9 \\
\hline 11 & 17.9 & 33.5 & 10.7 & -6.1 \\
\hline 12 & 26.4 & 31.2 & 10.6 & -8.7 \\
\hline 13 & 19.4 & 27.3 & 18.8 & -11.9 \\
\hline 14 & 28.8 & 35.3 & 9.2 & -6.1 \\
\hline 15 & 18.1 & 34.7 & 8.5 & -9.4 \\
\hline 16 & 26.0 & 25.2 & 13.3 & -10.3 \\
\hline 17 & 18.2 & 26.0 & 15.5 & -14.9 \\
\hline 18 & 21.9 & 39.1 & 20.7 & -11.8 \\
\hline 19 & 30.0 & 33.6 & 21.1 & -18.0 \\
\hline 20 & 26.7 & 35.7 & 23.1 & -19.1 \\
\hline
\end{tabular}

\section{$\square$ Unloaded $\square$ Fully loaded}

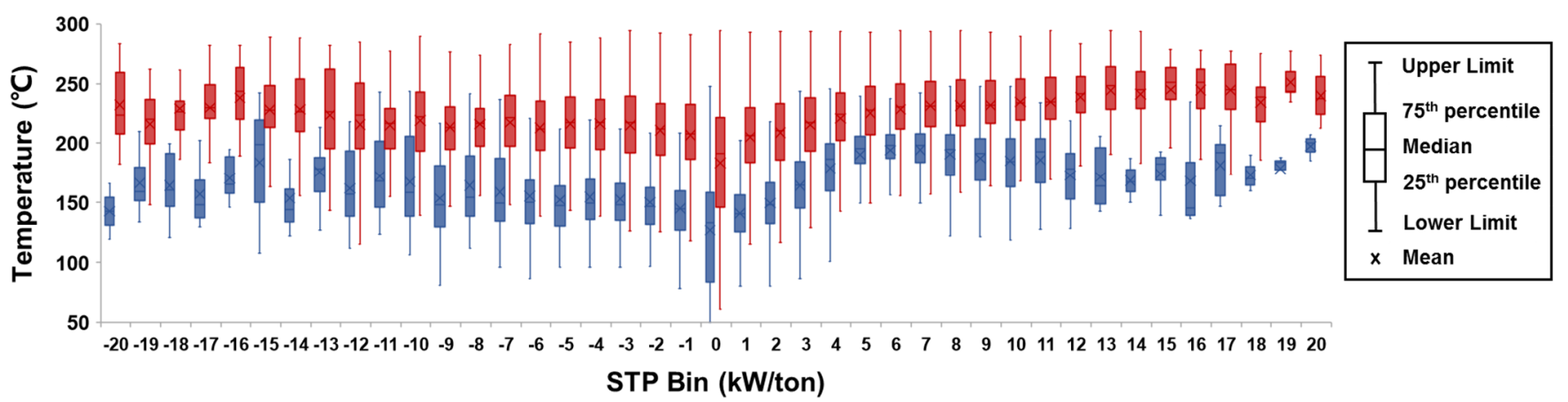

Figure 7. The difference in exhaust temperature between fully loaded and unloaded trucks. (IQR $=75$ th percentile -25 th percentile, Lower Limit $=\max ($ minimum in the sample, 25 th percentile $-1.5 \mathrm{IQR})$, Upper Limit $=\min ($ maximum in the sample, 75 th percentile $+1.5 \mathrm{IQR})$ ). 


\subsection{Characteristics of Emission Factors for DSTTTS under Different Loading Conditions}

Based on the calculation methods in the previous section, this study analyzed differences in the emission factors between unloaded and fully loaded trucks in each speed range, as shown in Figure 8. A variable $\beta(\%)$ represented the relative difference of emission factors between fully loaded and unloaded DSTTTs. It was difficult to obtain real-time load information of all trucks on the road network, resulting in the full-load state often being mistaken for the empty load status. Therefore, in this study, the misestimated fully loaded emission factor was obtained by calculating the fully loaded STP distribution using the unloaded weight and combining the unloaded trucks' emission rate, as shown in Figure 9. The calculation method of the emission factor measurement error caused by the fully loaded state being mistaken for the no-load state was shown in Equation (8):

$$
\operatorname{Error}_{j}\left(v_{k}\right)=\frac{E F_{\text {misestimated fullyloaded }-j}\left(v_{k}\right)-E F_{\text {fullyloaded }-j}\left(v_{k}\right)}{E F_{\text {fullyloaded }-j}\left(v_{k}\right)} \times 100 \%
$$

where, $\operatorname{Error}_{j}\left(v_{k}\right)=$ the relative difference of $j$ emission factors between fully loaded and misestimated-fully loaded DSTTTs at the speed bin $v_{k}(\%), E F_{\text {fullyloaded- } j}\left(v_{k}\right)=$ the emission factor of $j$ for fully loaded trucks at the speed bin $v_{k}(\mathrm{~g} / \mathrm{km})$, and $E F_{\text {misestimated fullyloaded- } j(v k)}$ $=$ the emission factor of $j$ for misestimated-fully loaded trucks at the speed bin $v_{k}(\mathrm{~g} / \mathrm{km})$.
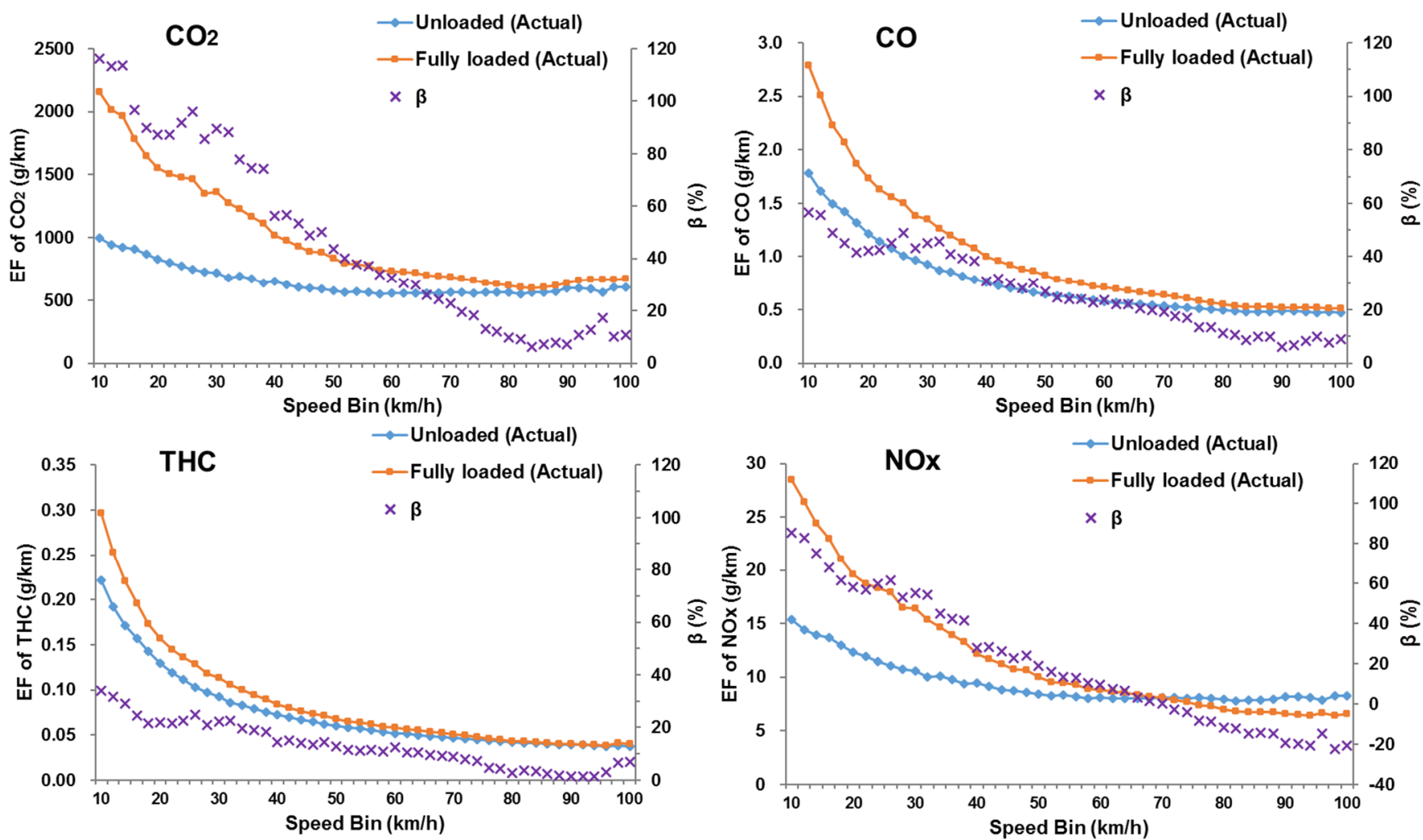

Figure 8. The emission factor differences of $\mathrm{CO}_{2}, \mathrm{CO}, \mathrm{THC}$ and $\mathrm{NO}_{\mathrm{x}}$ between fully loaded and unloaded status in each speed bin. 

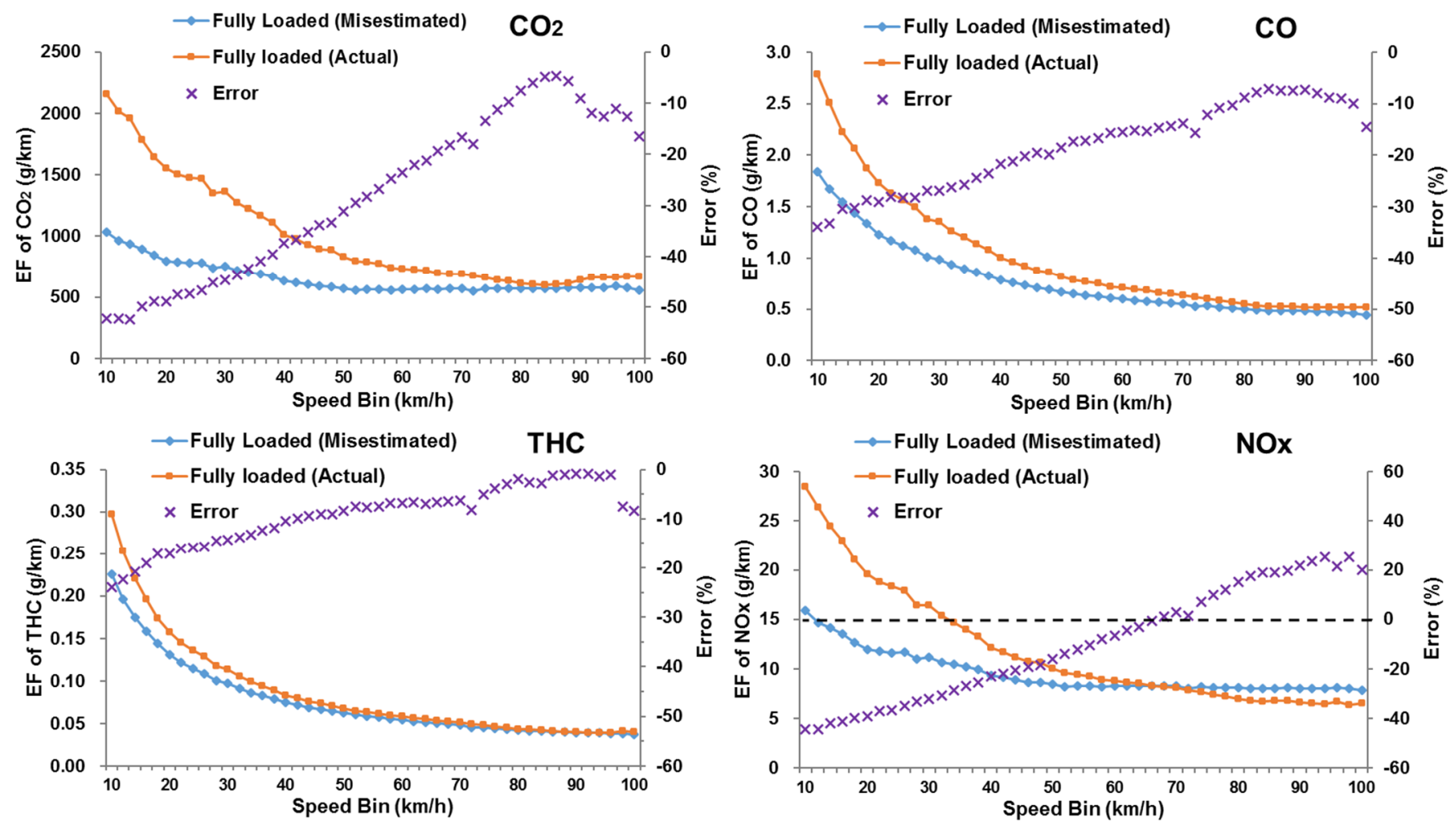

Figure 9. The emission factor differences of $\mathrm{CO}_{2}, \mathrm{CO}, \mathrm{THC}$ and $\mathrm{NO}_{x}$ between fully loaded and misestimated-fully loaded status in each speed bin. (emission factor of misestimated-fully loaded states was obtained by calculating the STP distribution using the $\mathrm{m}$ of unloaded trucks and combining with the emission rate of unloaded trucks.).

In Figures 8 and 9, the emission factors of all pollutants decreased as the operating speed increased. When the speed bin was $40 \mathrm{~km} / \mathrm{h}$ or less, the emission factor dropped sharply as the speed increased, while, when the speed was $40 \mathrm{~km} / \mathrm{h}$ or greater, the downward trend of the emission factor slowed down. There were specific noticeable differences noted between unloaded and fully loaded trucks as follows:

(1) For $\mathrm{CO}_{2}, \mathrm{CO}$, and THC, the emission factors of the fully-loaded DSTTTs in each speed bin were higher than those of the unloaded trucks. However, the $\mathrm{NO}_{\mathrm{x}}$ emission factors of the fully-loaded trucks were higher than that of the unloaded trucks when the speed bin was $66 \mathrm{~km} / \mathrm{h}$ or less, while the situation was opposite when the speed bin was $68 \mathrm{~km} / \mathrm{h}$ or greater.

(2) The analysis results revealed that the relative difference $\beta(\%)$ in emissions between different load states was closely related to truck operating speed. The loading state had the most significant effect on the $\mathrm{CO}_{2}$ emission factors and the weakest impact on THC emission factors. When the operating speed was low $(0-30 \mathrm{~km} / \mathrm{h})$, the load had the most significant impact on the emission factor, with $\beta(\%)$ values ranging from $27.8 \%$ to $96.2 \%$.

(3) The impact of the load on emissions gradually lessened with increasing speed. Since the power required by the truck to overcome aerodynamic drag increased ternary to the operating speed, the effect of the load on the power was gradually weakened. When the operating speed was medium $(30-60 \mathrm{~km} / \mathrm{h})$, the $\beta(\%)$ values of $\mathrm{CO}_{2}, \mathrm{CO}$, THC, and $\mathrm{NO}_{x}$ were $53.7 \%, 30.8 \%, 14.8 \%$, and $26.3 \%$, respectively. When the operating speed was high $(60-100 \mathrm{~km} / \mathrm{h})$, the $\mathrm{NO}_{\mathrm{x}}$ emission factor of the fully-loaded vehicle was lower than that of the unloaded vehicle, and the $\beta(\%)$ values of $\mathrm{CO}_{2}, \mathrm{CO}, \mathrm{THC}$, and $\mathrm{NO}_{x}$ were $15.3 \%, 13.1 \%, 5.4 \%$, and $-9.5 \%$, respectively.

(4) Mistaking the fully-loaded truck as being unloaded would seriously affect the result of emission measurement, as shown in Figure 9. In this context, at low speeds 
$(0-30 \mathrm{~km} / \mathrm{h})$, the emissions factors of $\mathrm{CO}_{2}, \mathrm{CO}, \mathrm{THC}$, and $\mathrm{NO}_{\mathrm{x}}$ were underestimated by $48.1 \%, 30.1 \%, 19.9 \%$, and $38.2 \%$, respectively. The average emission factor errors of $\mathrm{CO}_{2}, \mathrm{CO}$ and THC were $-29.6 \%,-19.5 \%$ and $-10.5 \%$, respectively. When the speed bin was $66 \mathrm{~km} / \mathrm{h}$ or less or the speed bin was $68 \mathrm{~km} / \mathrm{h}$ or greater, the average $\mathrm{NO}_{\mathrm{x}}$ emission factor errors were $-26.1 \%$ and $15.4 \%$, respectively.

\section{Conclusions}

STP distribution and emission rates are crucial factors affecting the emission of DSTTTs under different load states. An emission model of DSTTTs under different load states was established according to the field operating data collected by OBD and the emissions data obtained by PEMS. This study refined the STP computing method according to the load, making it practicable to analyze emissions for on-road trucks with various load states in the same traffic scenarios. Differences in STP distributions, emission rates, and emission factors for DSTTTs at various loads were analyzed. The most significant findings from this study can be summarized as follows:

(1) Mistaking the fully loaded vehicle as an unloaded one would significantly misestimated DSTTTs emissions. The emission factors of $\mathrm{CO}_{2}, \mathrm{CO}$, and THC were underestimated in all speed bins, while the emission factor of $\mathrm{NO}_{\mathrm{x}}$ was overestimated at speeds greater than $68 \mathrm{~km} / \mathrm{h}$. The largest errors in emission measurements were found in low speeds (0-30 km/h), where average emission factors for $\mathrm{CO}_{2}, \mathrm{CO}, \mathrm{THC}$, and $\mathrm{NO}_{\mathrm{x}}$ were underestimated by $48.1 \%, 30.1 \%, 19.9 \%$, and $38.2 \%$, respectively.

(2) There were significant differences in STP distributions for various loaded DSTTTs. The STP distribution of unloaded DSTTTs was more concentrated than that of the fully loaded and overloaded conditions. The peak value of STP distribution for the unloaded state was significantly higher than those for the fully loaded and overloaded states. The bottom of the Gaussian distribution for fully loaded and overloaded trucks was obviously wider than that for trucks with no loads.

(3) When the STP bin was $-10 \mathrm{~kW} /$ ton or greater, the emission rates of $\mathrm{CO}_{2}, \mathrm{CO}$, and THC for DSTTTs under fully loaded state were higher than those for the vehicles under an unloaded state within each STP bin. However, the $\mathrm{NO}_{\mathrm{x}}$ emission rate under fully loaded condition was not necessarily higher than that under the unloaded condition due to the influence of exhaust temperature. The $\mathrm{NO}_{\mathrm{x}}$ emission rate for DSTTTs in a fully loaded state was higher than that for trucks in an unloaded state when the STP bin was between $-10 \mathrm{~kW} /$ ton and $3 \mathrm{~kW} /$ ton, while the situation was opposite when the STP bin was $4 \mathrm{~kW} /$ ton or greater.

(4) The emission factors of DSTTTs evolving from unloaded to fully loaded were significantly different. The emissions factors of $\mathrm{CO}_{2}, \mathrm{CO}, \mathrm{THC}$, and $\mathrm{NO}_{\mathrm{x}}$ for fully loaded trucks increased the most at low speeds $(0$ to $30 \mathrm{~km} / \mathrm{h})$. The average growth rates of $\mathrm{CO}_{2}, \mathrm{CO}, \mathrm{THC}$, and $\mathrm{NO}_{\mathrm{x}}$ were $96.2 \%, 47.9 \%, 27.8 \%$, and $65.2 \%$, respectively. As the operating speed increased, the effect of load on emissions gradually weakened. On average, the growth rates of emission factors for fully loaded trucks versus unloaded trucks were $15.3 \%$ for $\mathrm{CO}_{2}, 13.1 \%$ for $\mathrm{CO}$, and $5.4 \%$ for THC at low speeds (60 to $100 \mathrm{~km} / \mathrm{h}$ ), while, conversely, the emissions factors of $\mathrm{NO}_{\mathbf{x}}$ for fully loaded trucks decreased by $9.5 \%$ due to the influence of exhaust temperature.

The emissions model proposed in this study is able to evaluate the differences in emission associated with various loading conditions and provided a potential method to adjust vehicle emissions according to load weight and traffic conditions. However, this study failed to obtain emissions data of DSTTTs in an overloaded state, and the effect of road type on DSTTTs' emissions has not been discussed. It is necessary to conduct a more in-depth study on more fine-grained load states and road types in the future.

Author Contributions: Conceptualization, X.W. and G.S.; methodology, X.W.; validation, X.W. and G.S.; formal analysis, X.W.; investigation, X.W.; resources, X.W., G.S. and H.Y.; data curation, X.W., G.S. and H.Y.; writing-original draft preparation, X.W.; writing-review and editing, X.W., G.S., 
Z.Z., Y.W. and L.Y.; supervision, G.S.; project administration, G.S.; funding acquisition, G.S. All authors have read and agreed to the published version of the manuscript.

Funding: This research was funded by the National Key R\&D Program of China \#2018YFB1600700, and the National Natural Science Foundation of China (NSFC) \#71871015.

Institutional Review Board Statement: Not applicable.

Informed Consent Statement: Not applicable.

Data Availability Statement: Data sharing not applicable.

Acknowledgments: The authors would like to thank the Key Laboratory of Transport Industry of Big Data Application Technologies for Comprehensive Transport and State Environmental Protection Key Laboratory of Vehicle Emission Control and Simulation (VECS) for providing the vehicle emissions and operational data.

Conflicts of Interest: The authors declare no conflict of interest.

\section{References}

1. Ministry of Ecological Environment of the People's Republic of China. China Vehicle Environmental Management Annual Report 2019; Beijing, China, 2019. Available online: http://www.mee.gov.cn/hjzl/sthjzk/ydyhjgl/201909/P020190905586230826402.pdf (accessed on 22 February 2021).

2. Brodrick, C.J.; Laca, E.A.; Burke, A.F.; Farshchi, M.; Li, L.; Deaton, M. Effect of Vehicle Operation, Weight, and Accessory Use on Emissions from A Modern Heavy-duty Diesel Truck. Transp. Res. Rec. 2004, 1880, 119-125. [CrossRef]

3. Frey, H.C.; Rouphail, N.M.; Zhai, H. Link-based Emission Factors for Heavy-Duty Diesel Trucks based on Real-world Data. Transp. Res. Rec. 2008, 2058, 23-32. [CrossRef]

4. Zhang, S.; Yu, L.; Song, G. Emissions Characteristics for Heavy-duty Diesel Trucks under Different Loads based on Vehicle-specific Power. Transp. Res. Rec. 2017, 2627, 77-85. [CrossRef]

5. Perugu, H.; Wei, H.; Yao, Z. Developing High-resolution Urban Scale Heavy-duty Truck Emission Inventory using the Data-driven Truck Activity Model Output. Atmos. Environ. 2017, 155, 210-230. [CrossRef]

6. Azevedo, J.A.H.; Cassiano, D.R.; Feitosa, B.B.; Araújo, R.S.; Cavalcante, F.S.Á.; Oliveira, M.L.M.; Bertoncini, B.V. Estimation of Emissions from Diesel Freight Transportation in Urban Areas Starting from STP Parameter. In Proceedings of the 95th Annual Meeting of the Transportation Research Board, Washington, DC, USA, 10-14 January 2016.

7. Burgard, D.A.; Bishop, G.A.; Stedman, D.H.; Gessner, V.H.; Daeschlein, C. Remote Sensing of In-use Heavy-Duty Diesel Trucks. Environ. Sci. Technol. 2006, 40, 6938-6942. [CrossRef]

8. Chellam, S.; Kulkarni, P.; Fraser, M.P. Emissions of Organic Compounds and Trace Metals in Fine Particulate Matter from Motor Vehicles: A Tunnel Study in Houston, Texas. J. Air Waste Manag. Assoc. 2005, 55, 60-72. [CrossRef]

9. Tschanz, F.; Amstutz, A.; Onder, C.H.; Guzzella, L. Feedback Control of Particulate Matter and Nitrogen Oxide Emissions in Diesel Engines. Control Eng. Pract. 2013, 21, 1809-1820. [CrossRef]

10. Jin, T.; Lu, K.; Liu, S.; Zhao, S.; Qu, L.; Xu, X. Chemical Characteristics of Particulate Matter Emission from A Heavy-duty Diesel Engine using ETC Cycle Dynamometer Test. Aerosol Air Qual. Res. 2017, 17, 406-411. [CrossRef]

11. Littera, D.; Cozzolini, A.; Besch, M.; Carder, D.; Gautam, M. Effect of Turbulence Intensity on PM Emission of Heavy-duty Diesel Trucks-Wind Tunnel Studies. Atmos. Environ. 2017, 162, 31-44. [CrossRef]

12. Bishop, G.A.; Holubowitch, N.E.; Stedman, D.H. Remote Measurements of On-Road Emissions from Heavy-Duty Diesel Vehicles in California, Year 5, 2012; University of Denver: Denver, CO, USA, 2013. Available online: http:/ /www.feat.biochem.du.edu/assets/ databases/Cal/CA_HDDV_final_report_2012_NREL_version.pdf (accessed on 22 February 2021).

13. Gallus, J.; Kirchner, U.; Vogt, R.; Börensen, C.; Benter, T. On-road Particle Number Measurements using A Portable Emission Measurement System (PEMS). Atmos. Environ. 2016, 124, 37-45. [CrossRef]

14. Liu, Z.; Ge, Y.; Johnson, K.C.; Shah, A.N.; Tan, J.; Wang, C.; Yu, L. Real-world Operation Conditions and On-road Emissions of Beijing Diesel Buses Measured by Using Portable Emission Measurement System and Electric Low-pressure Impactor. Sci. Total Environ. 2011, 409, 1476-1480. [CrossRef]

15. Gajendran, P.; Clark, N.N. Effect of Truck Operating Weight on Heavy-duty Diesel Emissions. Environ. Sci. Technol. 2003, 37, 4309-4317. [CrossRef] [PubMed]

16. Kecojevic, V.; Komljenovic, D. Impact of Bulldozer's Engine Load Factor on Fuel Consumption, $\mathrm{CO}_{2}$ Emission and Cost. Am. J. Environ. Sci. 2011, 7, 125-131. [CrossRef]

17. Yao, Z.; Wang, Q.D.; Zhang, Y.Z.; Shen, X. The Impact of Load on Emission from On-road Heavy-diesel Vehicle. Environ. Pollut. Control 2012, 34, 63-67. [CrossRef]

18. Song, J.; He, L.; Hu, J.; Hu, K.; Du, Q.; Zu, L.; Bao, X. Real-World Emission Characteristics of China II Heavy-Duty Diesel Trucks with Different Payloads. Environ. Pollut. Control 2019, 41, 34-40. [CrossRef]

19. Jiménez-Palacios, J.L. Understanding and Quantifying Motor Vehicle Emissions with Vehicle Specific Power and TILDAS Remote Sensing. Ph.D. Thesis, Massachusetts Institute of Technology, Cambridge, MA, USA, 1999. 
20. Song, G.; Yu, L.; Tu, Z. Distribution Characteristics of Vehicle Specific Power on Urban Restricted-Access Roadways. J. Transp. Eng. 2013, 138, 202-209. [CrossRef]

21. Lai, J.; Yu, L.; Song, G.; Guo, P.; Chen, X. Development of City-specific Driving Cycles for Transit Buses based on VSP Distributions: Case of Beijing. J. Transp. Eng. 2013, 139, 749-757. [CrossRef]

22. Li, C.; Yu, L.; Song, G. Improved Binning of Operating Modes in EPA Simulator Program for Transit Buses: Case Study in Beijing Transp. Res. Rec. 2017, 2627, 57-66. [CrossRef]

23. Thiruvengadam, A.; Besch, M.C.; Thiruvengadam, P.; Pradhan, S.; Carder, D.; Kappanna, H.; Gautam, M.; Oshinuga, A.; Hogo, H.; Miyasato, M. Emission Rates of Regulated Pollutants from Current Technology Heavy-duty Diesel and Natural Gas Goods Movement Vehicles. Environ. Sci. Technol. 2015, 49, 5236-5244. [CrossRef] [PubMed]

24. Wang, X.; Song, G.; Wu, Y.; Yu, L.; Zhai, Z. A NOx Emission Model Incorporating Temperature for Heavy-duty Diesel Vehicles with Urea-SCR Systems based on Field Operating Modes. Atmosphere 2019, 10, 337. [CrossRef]

25. Hsieh, M.F.; Wang, J. Development and Experimental Studies of a Control-oriented SCR model for a Two-catalyst Urea-SCR System. Control Eng. Pract. 2011, 19, 409-422. [CrossRef]

26. Yadav, D.; Kavaiya, A.R.; Mohan, D.; Prasad, R. Low Temperature Selective Catalytic Reduction (SCR) of NOx Emissions by Mn-doped Cu/ $\mathrm{Al}_{2} \mathrm{O}_{3}$ Catalysts. Bull. Chem. React. Eng. Catal. 2017, 12, 415-429. [CrossRef]

27. Development of Emission Rates for Heavy-Duty Vehicles in the Motor Vehicle Emissions Simulator MOVES2010; EPA-420-B-12-049; EPA: Washington, DC, USA, 2012. Available online: https://nepis.epa.gov/Exe/ZyPDF.cgi/P100F80L.PDF?Dockey=P100F80L.PDF (accessed on 18 March 2021). 